\title{
MENASCHE, Renata (Organizadora). Saberes e sabores da colônia. Alimentação e cultura como abordagem para o estudo do rural. Porto Alegre: UFR GS. Série Estudos e Pesquisa, 2015.
}

ARLENE RENK

Doutora em antropologia pelo Museu Nacional-UFRJ Professora na Universidade Comunitária Regional de Chapecó

Chapecó, Brasil

arlene@unochapeco.edu.br

$\mathrm{E}$ STAMOS DIANTE de uma forma perspicaz, inteligente e instigadora de abordar o rural por meio do estudo de saberes e sabores da colônia, envolvendo comunidades pomeranas, italianas e remanescentes de quilombos, com instituições tais como feiras, festas, fabricação de doces, agricultura, o dia a dia desses homens e mulheres, escolas, em suas diversas facetas públicas e privadas, sempre generosos em dispender horas e horas para com os pesquisadores. Renata Menasche, organizadora do volume, é pesquisadora cuidadosa, de vasta experiência, com outros volumes publicados creditado e com inúmeros artigos em periódicos. É docente e pesquisadora dos Programas de Pós Graduação em Antropologia da Universidade Federal de Pelotas e do Programa de Desenvolvimento Rural Universidade da Universidade Federal do Rio Grande do Sul. Participa, assiduamente, dos Grupos de Trabalho das Reuniões da Associação Brasileira de Antropologia.

Os autores e autoras foram cuidadosos na explicitação do que consiste o colonial, neste caso. Tomemos o título: Saberes e sabores da colônia. Os saberes e os sabores, deixemos ao encargo do teor dos capítulos. A circulação e a interpretação do livro fogem ao controle dos autores. Centremo-nos na categoria da colônia. Para que alguém, não familiarizado com a categoria, de outra região país e que possa equivocadamente remeter ao período histórico do Brasil Colônia. Menasche inicia explicitando referir-se aos "camponeses com origem na imigração europeia (p. 8)

O livro compreende quinze capítulos, antecedidos por primorosa introdução, assinada pela organizadora, situando o leitor dos capítulos a seguir. Preceitos éticos são explicitados nas primeiras páginas, na indicação dos recursos das pesquisas, os grupos de pesquisa nos quais se inserem e, principalmente, as concepções das quais partilham. Quais as razões que levaram autores e autoras a percorrer as sendas, num contexto de produtos homogeneizados até a colônia? A démarche foi inteligente, a opção em privilegiar o consumidor urbano que, a exemplo de uma política de consumo, partilha de um rural valorizado e demanda por alimentos "naturais", produzidos artesanalmente e em pequena escala. Este consumidor constitui um mercado de produtos coloniais, carregando valores afetivos, de valores diacríticos positivados.

Consequentemente, somos informados de que a alimentação será percebida como "expressão de um imaginário sobre o rural, constituído por moradores de centros urbanos em suas práticas de consumo", bem como às fronteiras cada vez mais esgarçadas entre o rural e o urbano, ao contrário do ocorria há algumas décadas. Os diversos capítulos trabalham nesse sentido, embora seja prevalecente o urbano visitar o rural, o urbano busca memorar e comemorar as raízes no e do rural, mesmo que imaginado. Daí a distinção de festas para a comunidade e aquelas para o público externo. 
Onze capítulos do livro têm como locus de pesquisa a Serra do Tapes, no sul riograndense, cujos personagens são colonos pomeranos, italianos e afrodescendentes. Quatro capítulos com matriz étnica localizam-se fora da Serra do Tapes. Um deles tem como campo empírico a primeira área de colonização alemã no Rio Grande do Sul, o Vale do Rio dos Sinos. O outro se situa, igualmente, no Rio Grande do Sul, mas são os italianos de Santa Maria. Desloca-se, geograficamente a Santa Catarina, ao Vale do Itajaí, com a colonização alemã. E o outro está centrado no Espírito Santo, entre os pomeranos.

O propósito da obra: como bem dito na introdução, a estratégia foi estudar alimentação e cultura como abordagem para o estudo do rural. Nesse sentido a coletânea alcançou plenamente o êxito. Alimentação e cultura trazem as marcar étnicas e de gênero. Comida e imagem são o relato etnográfico e trajetória do trabalho da equipe, esmiuçando as atividades, a partir da comida. Esta age como leitmotiv.

Na produção rural, fica evidente ao estudar as trajetórias familiares, tanto ao estudar os deslocamentos verticais quanto horizontais, as dissensões internas quando se aborda os movimentos ecológicos, os rompimentos, as oposições entre ecológicos e "veneneiros" (usando a categoria nativa). Neste caso, deparamo-nos frente a um campo, no sentido proposto por Bourdieu (2005), das correlações de força, das disputas por hegemonias, das disputas pelo monopólio da verdade "ecológica".

O tempo de outrora, que sempre sofre ruptura, mas menor que o atual, era mais generoso na reprodução social da linhagem das doceiras. Vários favores podem ser levados em conta na retração da linhagem. De um lado, a tradição do saber-fazer doceiro, que se distinguia pela singularidade e pelos utensílios "clássicos", encontra nos preceitos higiênicos da vigilância sanitária a padronização que não se coaduna com a tradição. Normas externas e tradição nem sempre dão bom casamento.

Etnicidade pode ser evocada em feira e festas entre italianos. Vejamos o caso da feira estudada por Zanini, Santa Maria. A autora centrou-se em feira de comida e em pesquisa etnográfica constatando a invocação da etnicidade italiana. Assegura que, além de alimentos, vendiam elementos simbólicos, memória, cheiros, sabores. A feira evocava italianidade, rememoração, narrativa. Trabalho primoroso dessa interlocução do alimento-simbólico que beira a Proust em $A$ Procura do tempo perdido.

Italianidade na Serra do Tapes é perceptível em duas festas com marcas diferenciadas: Festa de Sant`Ana e Festa do Dia do Vinho, como espaços da pesquisa, estudos inspirados nos trabalhos de Bourdieu em Béarn. Naquele caso, a população urbana "domina" o baile do interior deixando os celibatários locais excluídos do lazer. A festa de Sant'Ana é classificada pelas autoras como festa antiga e a festa do vinho como festa à antiga. A primeira, por manter os laços de sociabilidade e reciprocidade, organizada pela e para a comunidade. A segunda, ao contrário, tem como destino o público externo, com vistas a divulgar a produção local de vinhos. Recebe da Emater, Embrapa, de Universidade, da Prefeitura, Sindicato dos Trabalhadores Rurais. A festa a cada edição vai se "italianizando", ou seja, incorporando elementos da cultura italiana.

A pomeranização de festa em São Lourenço é perceptível pela Südoktoberfest [festa de outubro do sul], isto é, patrimônio alimentar e construção no extremo sul do Brasil. A posição social dos pomeranos de São Lourenço era de estigma, até meados dos anos 2000. Coube a Prefeitura investir na política do passado, na valorização da memória, no patrimônio familiar, na Südktoberfest. Nela a comida passa a ser o signo de identidade, ideologicamente concebida e escolhida, para marcar o pertencimento.

$\mathrm{Na}$ esteira do estigma transformado em emblema, a escola pode ser e espaço para revivescência étnica, a exemplo do narrado no capítulo "Sabores da colônia: a alimentação como estratégia da memória". O Núcleo Educamemória, da realização de Formação Continuada Docente, desencadeou o processo. "Pois comer será sempre necessário e dependerá dos produtos indispensáveis. O modo como fazem e como convivem impacta na cultura de modo geral" (p. 199).

A Segurança Alimentar perpassa os diversos capítulos e mostra a tensão entre a agricultura convencional e a de base ecológica, os processos de conversão e reconversão. A trajetória biográfica de Roni, comparando-a com a do moleiro Menocchio é exemplar e merece continuidade e aprofundamento para que possa produzir uma edição comparada. Cada época tem seus moleiros. Cada época tem suas inquisições. Mas o fundamental está nas interpretações realizadas. Vai aqui a sugestão de incorporar Jack Goody com o processo de letramento na formação do processo da racionalidade do pensamento ocidental e como operaria naquela em que opera a oralidade.

Das comunidades autorreconhecidas como comunidades remanescentes de quilombo, excelente o trabalho da memória e as ressignificações das práticas alimentares. A pesquisa foi realizada três comunidades negras rurais. O reconhecimento foi a partir da Constituição de 1988. Ficou marcado o estigma do território. Mais do que isso, houve a expropriação do território, muitas famílias trocando a terra por alimentos. Hoje, processo se encontra em vias de reconhecimento e valorização das comunidades negras rurais. Embora já tenham obtido a certidão de autorreconhecimento pela Fundação Palmares, a Titulação das terras é conflituosa e está em tramitação no INCRA.

Autoestima e estratégias encontram-se diante da (in)segurança alimentar. As narrativas remetem às privações do passado. Hoje, contam com renda e aposentadoria, superando em parte a privação. $\mathrm{Na}$ alimentação a comida do tempo antigo perpassa a memória. Há 
a incorporação da farinha de trigo do bolo de pedra, quitute típico. A relação entre colonos e brasileiros é marcado por distintividades. A sugestão para trabalhos futuros, poderia ser a elaboração de biografias no estilo de Menocchios, para ver e ouvir as interpretações e peculiaridades de agentes ágrafos a respeito de seu mundo, do mundo rural.

"Rezar, trocar, comer: esquemas de reciprocidade na produção alimentar de índios e colonos" é um capítulo instigante que aborda dois grupos étnicos, a partir do sistema de reciprocidade de Marcel Mauss, nas obrigações de dar, de receber e de retribuir.

Aborda a influência da religião na vida das pessoas, bem como o empoderamento destas e a decisões que tomam frente as Igrejas. O segmento comunitário que adere à ecologia, vale-se de cosmologia, de que orgânico seria mais valorizado aos olhos de Deus (p. 316). "A natureza é de Deus, e o homem precisa conservá-la”. (p. 316). Há um esquema de reciprocidade com Deus para a obtenção de alimentos, o dar e receber, é praticado por todos na comunidade. (p. 322).

$\mathrm{O}$ quadro da reciprocidade não se esgota entre humano, estende-se entre natureza e humanos, e do humano com o sagrado. $\mathrm{O}$ autor estabelece os nexos com os Mbyá-Guaranis, de hibridismo em três termos. $\mathrm{Na}$ roça Mbyá-Guarani, a reza torna a planta feliz; plantam para o gasto; bservam os rituais do cultivo.

As afinidades dos grupos consistem em que ambos encontrariam dificuldade de por em prática o plantio considerado ideal. Um, pela subordinação às grandes empresas de agroquímicos e outro pela perda de suas terras. Por essa razão, o autor considera as práticas alimentares um fato social total (Mauss), e para o autor um "fato cósmico total", "sendo que a compreensão dos sistemas culinários passa pela compreensão do cosmos" (p. 334).

Falar do rural não seria possível sem falar de gênero. Embora na maior parte dos artigos a temática tangencie, mas naqueles subscritos por Ellen Woortmann e no de Joana Bahia aparecem de forma mais clara. $\mathrm{O}$ primeiro dedica-se aos descendentes de alemães do sul Brasil. O segundo, aos pomeranos do Espírito Santo. Com maestria Woortmann recorre a estudos camponeses apontando como esses atribuíam o espaço de subordinação e papeis femininos naturalizados; aponta o papel das mulheres na literatura de viajantes e, principalmente, na modificação arquitetônica das casas. Nesse sentido, aponta periodização com alteração que encontra equivalência com a mudança na família e posição da mulher no interior deste. Wooortmann, apresentou o capítulo na literal construção da casa, que serve de abrigo e suas mudanças, nas diversas gerações e no espaço feminino.

Gênero entre os pomeranos do Espírito Santo está relacionado à ética luterana à vida regrada, no qual o pão adquire o caráter sagrado e étnico. $O$ locus de pesquisa é Santa Maria de Jetibá. O Pão adquire o papel feminino, presente em festas, como demarcador étnico, com semelhanças a Santa Catarina, na divisão entre o pão e polenta, delimitador étnico entre alemães e italianos. A sociabilidade e introdução dos preceitos religiosos passam pelo lado feminino, associando a mulher como guardiã da língua pomerana e alemã, espaços de circulação religiosa. Também como atributo feminino está o pão, que não pode faltar nas festas.

O ethos de trabalho, carrega representações religiosas, pioneirismo, boa virtude, despojamento. As festas étnicas, marcas da identidade, são organizadas pela mediadora, a Luterana, que tem papel de relevância na comunidade. Uma das principais é a festa da colheita, obedecendo ao calendário do hemisfério norte.

Seyferth dedica-se ao estudo da colonização e das mudanças do Vale do Itajaí em Santa Catrina, apontando as práticas de natureza simbólica referenciadas e práticas cotidianas ou não, instrumentalizando identidades étnicas. Aborda etnicidade associada aos hábitos alimentares observados no cotidiano e nas festas de apelo turístico. Outro conceito operado é o cozinha étnica de Alba (1990), no contexto americano. Comida é um marcador cultural facilmente metaformizado e convertido em tradição pela memória. Oktoberfest, Eisbein, Kassler, músicas típicas, roupas típicas, colonização simbolizada nos desfiles. Demais festas típicas, como Fenarreco, Fenachpp e Schutzenfest. Café colonial, Festa Pomerana

A identidade ampara-se na ancestralidade germânica nas manifestações de cunho "tradição colonial". Essa seria uma das razões da comida entre os símbolos da etnicidade.

Enfim, os capítulos responderam às diferentes perspectivas do rural, mediadas pelas questões étnicas, pela comida como idioma da etnicidade, apontando mudanças e persistências de traços étnicos, arranjos e narrativas. Desejamos a todos uma boa e leitura! 